\title{
Dementia: a global health priority - highlights from an ADI and World Health Organization report
}

\author{
Marc Wortmann*
}

\begin{abstract}
Alzheimer's Disease International is the worldwide federation of Alzheimer associations that represent people with dementia and their families. Alzheimer's Disease International has commissioned a number of World Alzheimer Reports since 2009 and was involved in the recently launched report Dementia: A Public Health Priority by the World Health Organization. From these reports, we can learn about the growing impact of Alzheimer's disease and other dementias on our societies and the need to take action. Developing national Alzheimer plans is a key tool for this action.
\end{abstract}

\section{Impact of dementia}

Alzheimer's disease and other dementias have a huge impact on the people with the disease and their families. In a survey that was carried out for the World Alzheimer Report 2012 on stigma, people with the disease and their family carers reported about it. Many feel marginalised and isolated, and lose their friends or are even misunderstood by their family members [1]. Caring for someone with dementia is a huge task and many people feel strained. Alzheimer associations are created all over the world by family members and dedicated physicians, who understand the need to create a structure for support and information.

Alzheimer's disease and other dementias are a global health challenge and are exceptional in size, costs and impact. In the year 2010 there were an estimated 35.6 million people with Alzheimer's disease and other dementias worldwide, according to research for the World Alzheimer Report 2009 [2]. This number will increase with an ageing world population and will reach 66 million by the year 2030 and 115 million by 2050 . The main increase will take place in low income and middle

*Correspondence: m.wortmann@alz.co.uk

Alzheimer's Disease International, 64 Great Suffolk Street, London, SE1 OBL, UK income countries, where more than $70 \%$ of the people with dementia will live by 2050 (Figure 1).

There is one new case of dementia diagnosed every 4 seconds, or 7.7 million cases per year [3], so we can also calculate that more than 600 million people in the world will live with this disease in the next 40 years. Our health systems are not prepared, both from social and economic perspectives. The World Alzheimer Report 2010 looked at the economic cost of dementia: in 2010 this was US $\$ 604$ billion, the equivalent of $1 \%$ of the global gross domestic product. If dementia was a country it would be the 18th largest in terms of gross domestic product, listed between Turkey and Indonesia (Figure 2). Medical costs account for less than $20 \%$ of this amount. The main costs are social care (for care homes and other care facilities) and informal care, because many people who care for a relative lose their jobs or need to start working part-time (Figure 3) [4].

\section{Alzheimer's Disease International}

Alzheimer's Disease International (ADI) is the worldwide federation of Alzheimer associations. Our 78 members are the leading representatives in their countries of people with Alzheimer's disease and related dementias and their families. The associations provide information and services - such as support groups, helplines and sometimes respite care - at the local and national levels, and advocate for the needs and rights of the people with the disease. The more emerged associations are putting an increased effort into funding basic, clinical and psychosocial dementia research. Alzheimer's associations in Australia, Canada, France, the Netherlands, the USA and the UK reported spending of $\$ 1$ million or more on research grants in the year 2011.

The main objectives of ADI are making dementia a global health priority, strengthening and supporting its member associations, and raising global awareness about the disease. A number of activities are carried out to achieve these objectives, including an annual international conference and the Alzheimer University training course. ADI has been in official relations with the World Health Organization since 1996 and with the United Nations since 2012. 


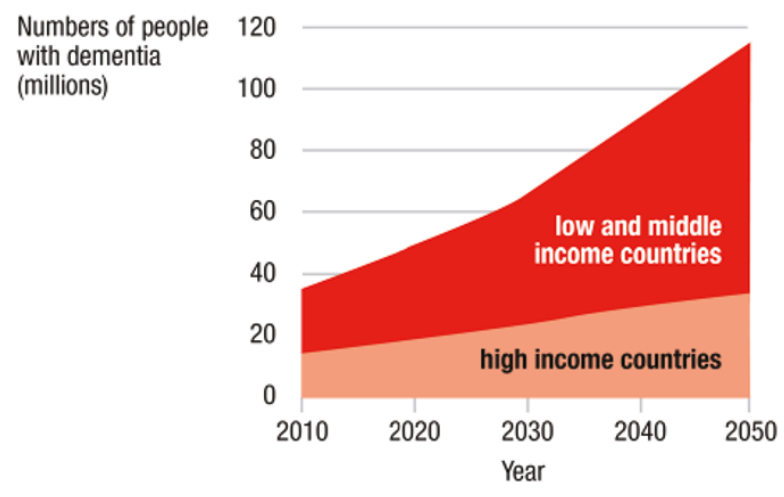

Figure 1. Growth in numbers of people with dementia in highincome countries and low income and middle income countries.

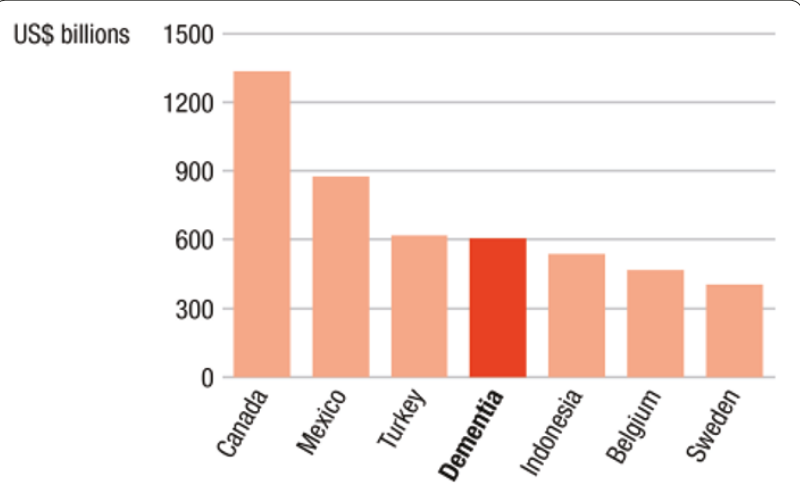

Figure 2. Cost of dementia compared with national economies.

To enhance global public policy on dementia, ADI has released reports on the global prevalence of dementia (World Alzheimer Report 2009), the economic cost of dementia (World Alzheimer Report 2010) and the benefits of early diagnosis and intervention (World Alzheimer Report 2011). ADI worked with the World Health Organization on the report Dementia: A Public Health Priority that was launched in Geneva in April 2012 [3] . This report confirms previous data and provides an overview for all aspects of the disease. The report recommends that every country should develop a national Alzheimer and dementia plan, and gives a framework for action. This framework includes the following stages [5].

The framework initially involves advocacy and awareness raising. Advocacy targets governments at all levels to encourage policies that will improve dementia care and services. Awareness raising focuses on the general public, as well as families and healthcare professionals, to improve their understanding of dementia and to change attitudes and practices.

Developing and implementing dementia policies and plans should be carried out across governmental departments on all medical, social, legal and economic aspects

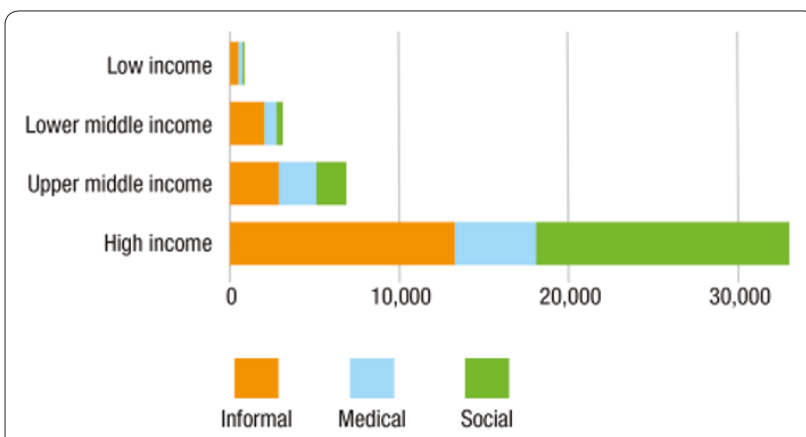

Figure 3. Care costs per person with dementia in different World Bank income groups. Costs in US\$.

of the disease. Plans should be put together and implemented in collaboration with academia, nongovernmental organisations, professional organisations and governmental departments and agencies.

The third stage of the framework concerns health and social system strengthening. It is essential that health and social systems are equipped to provide the range of care and services that people with dementia and family caregivers need. This includes capacity-building and education among healthcare professionals and investments in health information systems.

Finally, research and evaluation should complete the framework. Each country should develop a research agenda, and there is need for international collaboration and public/private partnerships to make progress in basic science and finding new and more effective treatments. The agenda will be multidisciplinary. Countries also need to monitor the course of the dementia epidemic for changes in prevalence and incidence that might indicate success or failure of measures.

ADI wants to work with its member organisations and other international nongovernmental organisations to make this framework happen.

A number of countries now have Alzheimer or dementia plans - for instance, Australia, South Korea, France, the UK, Norway and Denmark. The USA is working on a plan and has published a draft. There are also policy initiatives in Mexico and India. These plans are promising and other countries can learn from the first experiences. From the data, it is clear that we have no time to lose!

\section{Abbreviations}

ADI, Alzheimer's Disease International.

\section{Competing interests}

$M W$ receives a salary from ADI.

Published: 21 September 2012

\section{References}

1. World Alzheimer Report 2012, Overcoming the Stigma of Dementia [http://www.alz.co.uk/research/world-report-2012] 
2. World Alzheimer Report 2009 [http://www.alz.co.uk/research/files/WorldAlzheimerReport.pdf]

3. Dementia: A Public Health Priority [http://www.who.int/mental_health/ publications/dementia_report_2012/en/]

4. World Alzheimer Report 2010, The Global Economic Impact of Dementia [http://www.alz.co.uk/research/files/WorldAlzheimerReport2010.pdf]

5. World Health Organization and Alzheimer's Disease International: Dementia: A Public Health Priority. Geneva: World Health Organization; 2012:92-93. [http://www.who.int/mental_health/publications/dementia_report_2012/en/] doi:10.1186/alzrt143

Cite this article as: Wortmann M: Dementia: a global health priority highlights from an ADI and World Health Organization report. Alzheimer's

Research \& Therapy 2012, 4:40. 